\title{
Propionate induces the release of granules from bovine neutrophils
}

\author{
M. D. Carretta, I. Conejeros, M. A. Hidalgo, and R. A. Burgos ${ }^{1}$ \\ Laboratory of Inflammation Pharmacology, Institute of Pharmacology and Morphophysiology, Faculty of Veterinary Science, \\ Universidad Austral de Chile, PO Box 567, Valdivia, Chile
}

\section{ABSTRACT}

Short-chain fatty acids (SCFA) are produced by bacterial fermentation in the rumen of cattle and are the primary energy source in ruminants. Propionate is one of the main SCFA and it can exert multiple effects on the inflammatory process and neutrophil function via calcium $\left(\mathrm{Ca}^{2+}\right)$ release, reactive oxygen species, and intracellular $\mathrm{pH}$ changes. However, currently no evidence has shown whether propionate can induce granule release from bovine neutrophils. The purpose of this study was to analyze the effect of propionate on granule release and to evaluate the expression of two G-protein coupled receptors - GPR41 and GPR43 - that are activated by propionate. Neutrophil degranulation was assessed by quantifying the release of the neutrophil enzymes myeloperoxidase (MPO), lactoferrin, and matrix metalloprotease-9 (MMP-9) as markers of azurophil, specific granules, and gelatinase granules, respectively. Isolated bovine neutrophils were treated with millimolar concentrations of propionate $(0.3,3$ and $30 \mathrm{mM})$, and the cell-free supernatants were recovered. The stimulation of neutrophils with $0.3 \mathrm{~m} M$ propionate induced the release of lactoferrin and MMP-9 as revealed by ELISA and gelatin zymography, respectively. Propionate at 30 $\mathrm{m} M$ induced the release of MPO as demonstrated using an enzymatic assay. The role of intracellular $\mathrm{Ca}^{2+}$ influx and the signaling pathways that may regulate the propionate effect on granules release were also determined. Reverse transcription (RT)-PCR and real-time PCR were performed to analyze the expression of GPR 41 and GPR 43 mRNA in bovine neutrophils. Both mRNA were detected, whereas the expression of $G P R 43$ was higher than that of GPR 41, and the synthetic agonists for this receptor, phenylacetamides 1 and 2, caused an increase in intracellular $\mathrm{Ca}^{2+}$, lactoferrin, and MMP-9 release. These results support that propionate-induced granule release is mediated by intracellular $\mathrm{Ca}^{2+}$ influx and activation of extracellular signal-regulated kinase ERK 1/2. We also propose a potential role of GPR43

Received August 31, 2012.

Accepted December 17, 2012.

${ }^{1}$ Corresponding author: rburgos1@uach.cl in propionate-induced granule release from bovine neutrophils that may be involved in regulatory effects of propionate in the innate immune response in cattle.

Key words: short-chain fatty acid, G-protein coupled receptor GPR43, bovine neutrophil, neutrophil granule

\section{INTRODUCTION}

Neutrophils are critical for the initial defense of the host against invading microbial pathogens in cattle (Paape et al., 2003). Two different microbicidal mechanisms occur within the neutrophils: the oxidative and the nonoxidative systems. The oxygen-dependent mechanism acts through the generation of reactive oxygen species, and the oxygen-independent mechanism acts through the production of antimicrobial peptides and proteolytic enzymes (Burvenich et al., 2003). Most of the steps in this process depend on the mobilization of cytoplasmic granules and secretory vesicles. At least 4 types of granules and vesicles have been classified in human neutrophils, including primary granules (also termed azurophilic granules), secondary and tertiary granules (also termed specific and gelatinase granules, respectively), and a group of highly mobilizable secretory vesicles (Faurschou and Borregaard, 2003; Borregaard et al., 2007). Several granule types have been characterized in bovine neutrophils, some of which are analogous to the granules found in human neutrophils, such as the specific and azurophilic granules. However, bovine neutrophils contain a unique granule (known as the large granule) that is not present in human cells (Gennaro et al., 1983). Additionally, bovine neutrophils may differ in the important functional characteristics of human neutrophils, such as their lack of receptors for $N$-formylated peptides (Brown and Roth, 1991).

The secretion of neutrophil granules can be triggered after stimulation of a receptor, usually a 7-transmembrane $\mathrm{G}$ protein-coupled receptor, which causes an increase in the intracellular calcium $\left(\mathrm{Ca}^{2+}\right)$ levels and activation of distal signaling pathways (Lacy and Eitzen, 2008). In this sense, a strict rank order of exocytosis of the 4 compartments (secretory vesicles, gelatinase granules, specific granules, and azurophil granules) has been observed when cytosolic $\mathrm{Ca}^{2+}$ is elevated using a 
calcium ionophore or formyl-Met-Leu-Phe (fMLP) in human neutrophils (Sengeløv et al., 1993). In bovine neutrophils, increasing concentrations of platelet-activating factor (PAF) caused an increase in the intracellular $\mathrm{Ca}^{2+}$ and progressively mobilized the secretory vesicles, specific granules, and at extremely high doses, azurophil granules (Swain et al., 1998). In addition to the intracellular $\mathrm{Ca}^{2+}$ increase, members of the mitogen-activated protein kinase (MAPK) family, which includes ERK1/2 and p38 MAPK, have been shown to mediate granule exocytosis (Lacy and Eitzen, 2008). In bovine neutrophils, the signaling events between the activation of G-protein-coupled receptors and the exocytosis of neutrophil granules are largely unknown.

Short-chain fatty acids (SCFA) are the principal byproducts of fiber fermentation in the gastrointestinal tract and are the primary energy source in ruminants (Bergman, 1990). The total SCFA concentration in the rumen is normally between 70 and $130 \mathrm{mM}$, and SFCA are rapidly absorbed into the bloodstream (Bergman, 1990). Propionate is one of the main SCFA and it exerts multiple effects on human neutrophil function, including $\mathrm{Ca}^{2+}$ release (Naccache et al., 1988), superoxide production (Nakao et al., 1998), and cytoskeletal actin distribution (Brunkhorst et al., 1992), and it induces chemotaxis in vitro (Le Poul et al., 2003; Vinolo et al., 2011a), suggesting a potential role as a modulator of the innate immune response. In cattle, propionate exerts similar effects as in human neutrophils, including intracellular acidification, $\mathrm{Ca}^{2+}$ release, superoxide production, and ERK1/2 activation (Sandoval et al., 2007a). However, little is known about the effect of propionate on granule release in bovine neutrophils. Recently, Wang et al. (2009) demonstrated that the bovine genome encodes functional G-protein coupled receptors GPR41 (free fatty acid receptor 3, FFA3) and GPR43 (FFA2), 2 previously described receptors that can be activated by SCFA. Activation of GPR41 and GPR43 is coupled with several intracellular signals, such as inositol trisphosphate generation, elevated intracellular $\mathrm{Ca}^{2+}$ release, and ERK1/2 activation (Brown et al., 2003; Le Poul et al., 2003). In addition, these genes, especially human and bovine GPR43, are highly expressed in hematopoietic tissues (spleen and bone marrow), supporting a putative role of SCFA in immune cell activation in cattle (Le Poul et al., 2003; Wang et al., 2009). In fact, a discrepancy exists in the role of SCFA in the regulation of the inflammatory response. The most common action of SCFA is their antiinflammatory effect, inhibiting the stimuli-induced expression of adhesion molecules (Zapolska-Downar and Naruszewicz, 2009) and suppressing the production of proinflammatory mediators (Cox et al., 2009). In contrast, a proinflammatory action of SCFA has been observed, mainly due to the ability of SCFA to induce neutrophil migration in different species (Vinolo et al., 2011b). In cattle, the influence of intraluminal SCFA on inflammation in the colon is well documented and is likely the mechanism that triggers the inflammatory response in the ruminal epithelium (Mortensen and Clausen, 1996). Because granule release is involved in tissue damage during migration of neutrophils, we hypothesized that propionate could induce release of granules from bovine neutrophils and modulate the inflammatory process during nutrition imbalance in ruminants.

In the present study, we demonstrated that propionate induces primary, secondary, and tertiary granule release and characterized the signaling mechanisms that regulate this process. We also showed a high expression of GPR43 receptors in bovine neutrophils and demonstrated that the propionate effects were mimicked by the synthetic GPR43 agonists phenylacetamides 1 and 2. These data can contribute to the understanding of the mechanisms of propionate in the inflammatory response in cattle.

\section{MATERIALS AND METHODS}

\section{Animals}

Five clinically healthy, nonpregnant black Friesian dairy heifers were used in all experiments. The animals were maintained in the Universidad Austral de Chile herd and routinely checked by a veterinarian. The physiological parameters monitored include respiratory rate, heart rate, rectal temperature, and body condition. The heifers were fed twice daily, and the daily ration was divided into meals of equal size of $1.0 \mathrm{~kg} / \mathrm{d}$ of concentrate. Heifers grazed a naturalized pasture composed mainly of perennial grasses, the most abundant being Holcus lanatus (common velvetgrass) and Agrostis capillaris (colonial bentgrass). The contribution of forage legumes was low $(<10 \%$ of DM). The experiments were conducted in accordance with the Ethical Committee of the Universidad Austral de Chile.

\section{Study Design}

Figure 1 shows an overview of the experimental study design. First, blood samples from black Friesian dairy heifers were collected and neutrophils were isolated. Then, the dose and time responses of propionate were evaluated by incubating the neutrophils with different concentrations of propionate for different times. To determine the role of $\mathrm{Ca}^{2+}$ and the signaling pathway on release of granules induced by propionate, the neutrophils were pretreated with $\mathrm{Ca}^{2+}$ blockers and signaling 


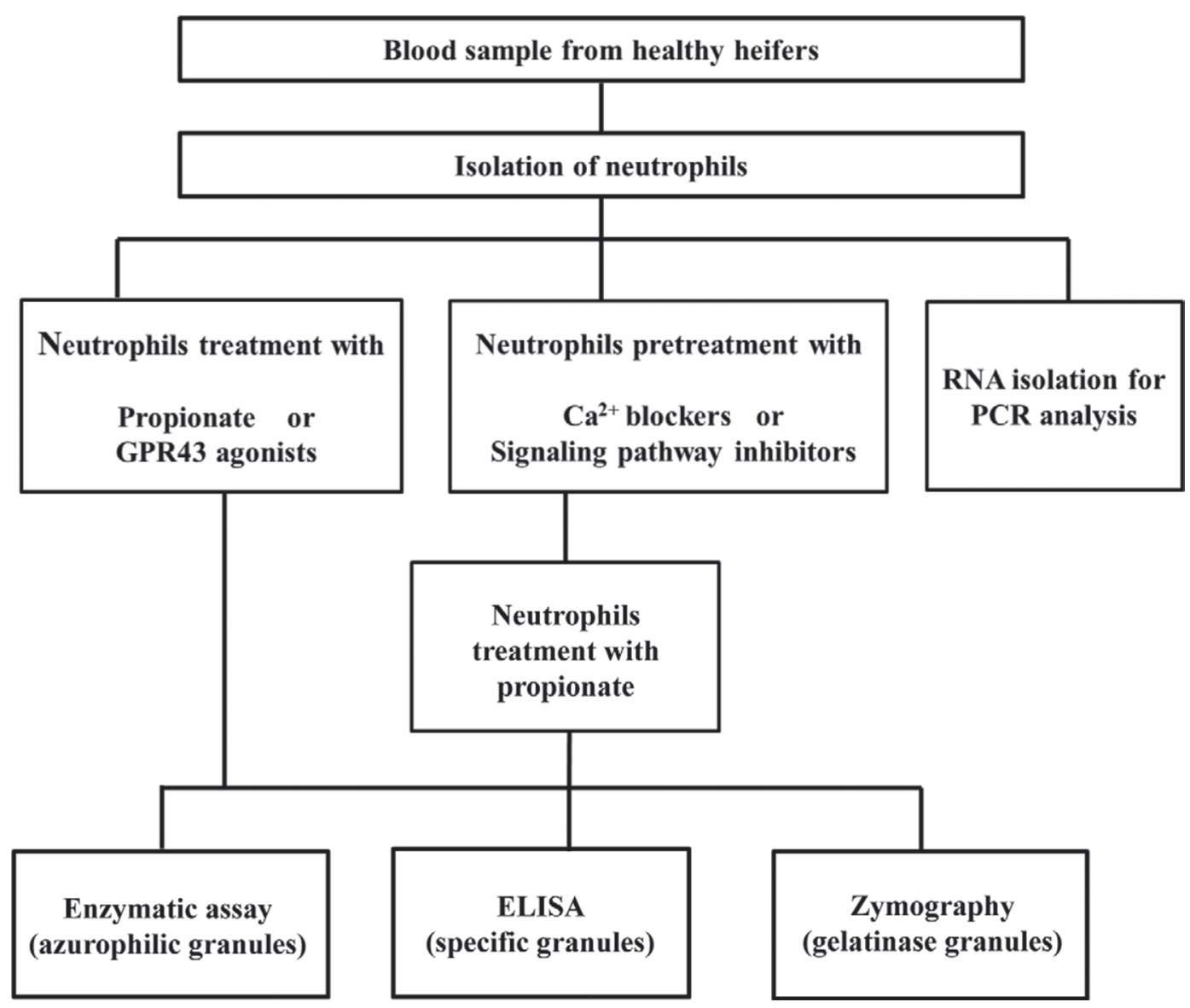

Figure 1. Schematic overview of the study design. After isolation from dairy heifers, the neutrophils were treated with propionate or the G-protein coupled receptor GPR43 agonists. In other sets of experiments, neutrophils were pretreated with calcium blockers or signaling pathways inhibitors. Expression of GPR 41 and $G P R 43 \mathrm{mRNA}$ was measured by real-time PCR.

pathway inhibitors and then stimulated with propionate at concentration and times based on previous experiments. The RNA was isolated from bovine neutrophils to analyze the expression of GPR 41 and GPR 43 by real-time PCR. Finally, to evaluate if the GPR43 receptor is involved in granule release induced by propionate, the neutrophils were treated with GPR43 agonists and granule markers was evaluated.

\section{Blood Sampling and Neutrophil Purification}

Blood samples were collected aseptically by jugular venipuncture from the heifers. Blood samples $(40 \mathrm{~mL})$ from each animal were collected in Vacutainer tubes (Becton Dickinson, San Diego, CA) containing $150 \mu \mathrm{L}$ of acid citrate dextrose as anticoagulant. Neutrophils were isolated according to the method of Roth and Kaeberle (1981). Briefly, the blood was gently rocked for $5 \mathrm{~min}$ and then centrifuged at $1,000 \times g$ for 20 min. The plasma and buffy coat were aspirated, and the remaining red blood cells and neutrophils were sus- pended in Hanks' balanced salt solution (HBSS). The red blood cells were removed by flash hypotonic lysis using a cold phosphate-buffered water solution $(5.5 \mathrm{mM}$ $\mathrm{NaH}_{2} \mathrm{PO}_{4}, 8.4 \mathrm{mM} \mathrm{HK}_{2} \mathrm{PO}_{4}$, pH 7.2). After returning to isotonicity using a hypertonic phosphate-buffered solution (5.5 mM NaH $\mathrm{PO}_{4}, 8.4 \mathrm{mM} \mathrm{HK}_{2} \mathrm{PO}_{4}, 0.46 M$ $\mathrm{NaCl}, \mathrm{pH} 7.2$ ), the sample was centrifuged at $600 \times g$ for $10 \mathrm{~min}$. The remaining neutrophil pellet was then washed with HBSS a total of 3 times. For the experiments, neutrophils were suspended in HBSS with 0.9 $\mathrm{m} M \mathrm{CaCl}_{2}$. All centrifugation steps occurred at room temperature $\left(20^{\circ} \mathrm{C}\right)$. Cell viability was assessed with the trypan blue exclusion test and was never less than $97 \%$. Neutrophil purity was assessed by flow cytometry using the FACSCanto II cytometer (BD Biosciences, San Diego, CA) and was never less than $95 \%$.

\section{Neutrophil Degranulation}

To determine the dose response of propionate (Sigma Chemical Co., St. Louis, MO) on specific, gelatinase, 
and azurophil granules release, $1 \times 10^{6}$ cells in HBSS with $0.9 \mathrm{mM} \mathrm{CaCl} l_{2}$ were incubated with $0.3,3$, and 30 $\mathrm{m} M$ propionate for $30 \mathrm{~min}$ at $37^{\circ} \mathrm{C}$. The positive controls for degranulation were $5 \mu \mathrm{g} / \mathrm{mL}$ ionomycin (Sigma Chemical Co.) and $100 \mathrm{n} M \mathrm{PAF}$ (Calbiochem, La Jolla, $\mathrm{CA}$ ). To study the kinetics of granule release, the neutrophils were incubated for periods ranging from 0 to $30 \mathrm{~min}$. Afterward, the cells were centrifuged at $600 \times$ $g$ for $6 \mathrm{~min}$, and $300 \mu \mathrm{L}$ of the supernatant was recovered and used for the analysis of lactoferrin release and gelatinase activity. Also, the neutrophils were treated for 10 min with 0.1 to $10 \mu M$ phenylacetamides 1 and 2. The GPR43 agonists were synthesized at Amgen Inc. (South San Francisco, CA). They were dissolved in 10 $\mathrm{m} M$ dimethyl sulfoxide (DMSO) and subsequently diluted in HBSS with $0.9 \mathrm{mM} \mathrm{CaCl} 2$. The final DMSO concentration in the media was $0.1 \%$ ( $\mathrm{vol} / \mathrm{vol}$ ).

\section{Effect of Calcium and Intracellular Signaling Pathway Inhibitors}

The neutrophils were treated with $0.3 \mathrm{mM}$ ethylene glycol tetraacetic acid [EGTA, ethylene glycolbis(2-aminoethylether)- $N, N, N^{\prime}, N^{\prime}$-tetraacetic acid], a $\mathrm{Ca}^{2+}$ chelator, for $30 \mathrm{~s} ; 2 \mu M$ U73122 (Calbiochem), a phospholipase C (PLC) inhibitor, for $5 \mathrm{~min}$; or 50 $\mu M$ 2-aminoethoxydiphenyl borate (2-APB; Sigma Chemical CO.), a putative store-operated calcium entry (SOCE) inhibitor, for $10 \mathrm{~min}$ before stimulation with propionate. To investigate the intracellular signaling pathways involved in the granule release induced by propionate, the cells were pretreated for $10 \mathrm{~min}$ with the following inhibitors (each tested singly): 10 $\mu M$ UO126 (Calbiochem), a MAPK MEK1/2 inhibitor that blocks the phosphorylation of ERK1/2; $1 \mu M \mathrm{SB}$ 203580 (Calbiochem), a p38 MAPK inhibitor; $0.1 \mu M$ Src inhibitor I (Calbiochem), a potent inhibitor of Src family tyrosine kinases; and $1 \mu M$ LY294002 (Promega, Madison, WI), a phosphatidylinositol 3-kinase (PI3K) inhibitor, before the stimulation with propionate. All inhibitors were dissolved in DMSO. Finally, to test if the (pertussis toxin-sensitive) $G_{i} / G_{0}$ subfamily of $G$ proteins were involved in the signal transduction induced by propionate, the cells were incubated with 200 $\mathrm{ng} / \mathrm{mL}$ pertussis toxin (PT; Calbiochem) for $1 \mathrm{~h}$ before the treatment with propionate.

\section{Determination of Primary Granule Release}

The exocytosis of the primary granules was determined according to a previously described method (Quade and Roth, 1997) based on the myeloperoxidase (MPO) $-\mathrm{H}_{2} \mathrm{O}_{2}$ oxidation of $3,3^{\prime}, 5,5^{\prime}$-tetramethylbenzi- dine (TMB; Invitrogen, Eugene, OR). Briefly, $1.25 \times$ $10^{6}$ neutrophils in $150 \mu \mathrm{L}$ were added to 96 -well plates and treated with the inhibitors as in the previous section. Then, the cells were treated with $5 \mu \mathrm{g} / \mathrm{mL}$ cytochalasin B (Sigma Chemical Co.) and $30 \mathrm{~m} M$ propionate for 5 min at $39^{\circ} \mathrm{C}$. The detergent cetyltrimethylammonium bromide (CTAB, $0.02 \%$ in water; Sigma Chemical Co.) was used as the lysing agent to determine the total MPO content of the neutrophils. Then, $50 \mu \mathrm{L}$ of prewarmed TMB containing $\mathrm{H}_{2} \mathrm{O}_{2}$ was added to each well. The color change reaction was allowed to proceed for $2 \mathrm{~min}$, and then $50 \mu \mathrm{L}$ of $4 M$ sulfuric acid was added to stop the reaction. The plates were centrifuged at $600 \times g$ for $10 \mathrm{~min}$, and $200 \mu \mathrm{L}$ of the supernatant was transferred to flat-bottomed, 96-well plates. The optical density (OD) was determined at $405 \mathrm{~nm}$ in a Varioskan microplate reader (Thermo Fisher Scientific, Wilmington, DE). The percentage release of MPO was calculated using the following formula: $\%$ release $=$ [(OD stimulated - OD background $) /(\mathrm{OD}$ lysed - OD background)] $\times 100$.

\section{Determination of Specific Granule Release}

Exocytosis of the specific granules was determined by measuring lactoferrin release in the cell-free neutrophil supernatants with a commercially available ELISA kit for bovine lactoferrin (Bovine Lactoferrin ELISA Quantitation Set, Bethyl Laboratories, Montgomery, TX). Briefly, $100 \mu \mathrm{L}$ of diluted coating antibody was added to each well and incubated for $1 \mathrm{~h}$. The antibody was diluted in coating buffer (50 $\mathrm{m} M$ carbonate-bicarbonate, $\mathrm{pH}$ 9.6). Then, $200 \mu \mathrm{L}$ of blocking solution $(50 \mathrm{mM}$ Tris, $0.14 M \mathrm{NaCl}, 0.05 \%$ Tween $20, \mathrm{pH} 8.0$ ) was added and incubated for $30 \mathrm{~min}$. Next, $100 \mu \mathrm{L}$ of standard or sample was added to each well and incubated for $1 \mathrm{~h}$. Then, $100 \mu \mathrm{L}$ of diluted horseradish peroxidase (HRP) detection antibody was added and incubated for $1 \mathrm{~h}$. Finally, $100 \mu \mathrm{L}$ of TMB solution was added in a dark room for approximately $10 \mathrm{~min}$. The reaction was stopped by adding $100 \mu \mathrm{L}$ of Stop Solution $(0.18 \mathrm{M}$ $\mathrm{H}_{2} \mathrm{SO}_{4}$; Invitrogen, Eugene, OR) to each well. Between all steps, the plate was washed 5 times, and all steps were performed at room temperature. The absorbance was measure in a Varioskan microplate reader (Thermo Fisher Scientific) set at $450 \mathrm{~nm}$. The results were expressed as lactoferrin concentration $(\mathrm{ng} / \mathrm{mL})$.

\section{Determination of Gelatinase Granule Release by Gelatin Zymography}

Zymography was performed as described previously by Conejeros et al. (2012). Briefly, $10 \mu \mathrm{L}$ of the su- 
pernatant was loaded onto a $10 \%$ polyacrylamide gel containing $0.28 \%$ gelatin. The gel was run at $200 \mathrm{~V}$ for $1 \mathrm{~h}$ in a Bio-Rad Mini Protean II apparatus (Bio-Rad Laboratories, Hercules, CA) and then soaked twice in $2.5 \%$ Triton $\mathrm{X}-100$ in distilled water on a shaker at room temperature for $1 \mathrm{~h}$. Afterward, the gel was soaked in a reaction buffer consisting of $100 \mathrm{~m} M$ Tris ( $\mathrm{pH}$ 7.5) and $10 \mathrm{mM} \mathrm{CaCl}{ }_{2}$ at $37^{\circ} \mathrm{C}$ overnight. The gel was stained in $0.5 \%$ Coomassie Brilliant Blue R-250 (Winkler, Santiago, Chile) in acetic acid:methanol:water (1:3:6). Evidence of enzymatic activity was determined by nonstaining areas where the gelatin had been degraded. The calculation of the apparent molecular masses of the gelatinolytic bands was made by referring to a standard prestained molecular mass marker. To measure the activity, the gels were digitalized, and the intensity of the bands was quantified by densitometry using the ImageJ 1.35s software (NIH, Bethesda, MD).

\section{Intracellular Calcium Measurement}

For the experiments, neutrophils were loaded with the $\mathrm{Ca}^{2+}$-sensitive fluorophore Fura-2AM $(2.5 \mu M$; Molecular Probes, Eugene, OR) for $30 \mathrm{~min}$ at $37^{\circ} \mathrm{C}$. The cells were washed, and $2 \times 10^{6}$ cells $/ \mathrm{mL}$ were suspended in HBSS containing $0.9 \mathrm{mM} \mathrm{CaCl}$. In some experiments, the cells were then washed and suspended in calcium-free HBSS with $0.3 \mathrm{~m} M$ EGTA. Flux of $\mathrm{Ca}^{2+}$ was measured at $37^{\circ} \mathrm{C}$ using the LS55 thermoregulated spectrofluorimeter (Perkin-Elmer Life Science, Waltham, MA). Fluorescence signals were acquired at $510 \mathrm{~nm}$ emission using dual excitation at $340 \mathrm{~nm}$ and $380 \mathrm{~nm}$.

\section{RNA Isolation and RT-PCR Analysis}

Total RNA was isolated from bovine neutrophils using the E.Z.N.A total RNA kit (Omega Bio-Tek, Norcross, GA) following the manufacturer's instructions. The samples were treated with ribonuclease-free deoxyribonuclease I (Turbo DNA-free assay, Ambion, UK) to remove genomic DNA, and the RNA was quantified using a NanoDrop 2000 Spectrophotometer (Thermo Fisher Scientific). For the cDNA synthesis, $200 \mathrm{ng}$ of RNA was reverse-transcribed in the presence or absence of reverse transcriptase using Affinity Script RT (Stratagene, La Jolla, CA). The PCR reaction was performed using GoTaq Green Master Mix (Promega) with $20 \mathrm{ng}$ of cDNA. The primers for GPR41 and GPR43 used in this study were previously designed and optimized by Wang et al. (2009); GAPDH cDNA was amplified as a housekeeping control. The PCR conditions were 30 cycles of $94^{\circ} \mathrm{C}$ for $30 \mathrm{~s}, 60^{\circ} \mathrm{C}$ for $1 \mathrm{~min}$, and $72^{\circ} \mathrm{C}$ for 1 min. The products were resolved on a $2 \%$ agarose gel and stained with ethidium bromide for analysis.

\section{Real-Time PCR Analyses}

The real-time PCR was conducted in triplicate using Brilliant II SYBRGreen QPCR (Stratagene). The PCR reaction was run for 40 cycles using the following protocol: 40 cycles of $95^{\circ} \mathrm{C}$ for $30 \mathrm{~s}, 55^{\circ} \mathrm{C}$ for $1 \mathrm{~min}$, and $72^{\circ} \mathrm{C}$ for $30 \mathrm{~s}$. The post-PCR melting curves confirmed the specificity of the single-target amplification. The abundance of each gene was calculated relative to $G A P D H$ mRNA using the formula: relative abundance $=2^{(-\Delta \mathrm{Ct})}$, where $\Delta \mathrm{Ct}$ is calculated as the difference between the Ct (cycle threshold) of GPR 41 or GPR 43 and GAPDH.

\section{Statistical Analysis}

The results are illustrated in bar graphs as the mean \pm SEM of independent experiments. One-way ANOVA was performed, and Dunnett's multiple comparison test was applied, using a significance level of $5 \%$. For the mRNA expression analysis, a Student's t-test was performed. All analyses were conducted with the Graph Pad Prism v5.0 software (Graphpad Software Inc., San Diego, CA). The dose-response curves of $\mathrm{Ca}^{2+}$ influx by the GPR43 agonists were expressed as a percentage of the phenylacetamide 2 maximum response. The dose-response curves of degranulation were expressed as a percentage increase above the basal unstimulated level and analyzed using a nonlinear regression method with the Graph Pad Prism v5.0 software (Graphpad Software Inc.).

\section{RESULTS}

\section{Propionate Induces the Rapid Release of MPO, Lactoferrin, and MMP-9 from Bovine Neutrophils}

To examine neutrophil degranulation after propionate stimulation, we quantified the release of MPO, lactoferrin, and matrix metalloprotease-9 (MMP-9) - markers of azurophil, specific granules, and gelatinase granules, respectively - into the extracellular milieu. Freshly isolated bovine neutrophils were incubated with various concentrations of propionate for $10 \mathrm{~min}$ (lactoferrin and MMP-9) or 30 min (MPO), and the cell-free supernatants were then collected and assayed for the presence of the granule markers. To measure the release of MPO, the cells were incubated with cytochalasin B, which has been used extensively to enhance the extracellular release of the granule content in response to stimulation (Quade and Roth, 1997). Additionally, we used 
the calcium ionophore ionomycin as a positive control of primary granule exocytosis. As shown in Figure 2A, $30 \mathrm{~m} M$ propionate significantly stimulated MPO secretion $(P<0.05)$ compared with the control. Next, we investigated the minimum time required to induce a significant release of these granules from bovine neutrophils, which were stimulated for $0,5,10,20$, or 30 min. We observed that MPO release was maximal by 5 min (Figure 2B). Lactoferrin release was quantified by ELISA, and we observed that $0.3 \mathrm{~m} M$ propionate induced lactoferrin release (Figure 2C), which was maximal at $10 \mathrm{~min}$ (Figure 2D). We used $100 \mathrm{n} M \mathrm{PAF}$, a well-known stimulant, to induce this granule type in bovine neutrophils (Swain et al., 1998, 2000). Gelatin zymography revealed that 0.3 and $3 \mathrm{~m} M$ propionate induced a significant release of MMP-9 $(P<0.01$ and $P<0.05$, respectively), visualized as gelatinase activity at $92 \mathrm{kDa}$ (Figure 2E) and that $100 \mathrm{n} M$ PAF induced a strong MMP-9 release, as we previously demonstrated in bovine neutrophils (Conejeros et al., 2012). We observed that the MMP-9 release was maximal at 10 min (Figure 2F). Based on these results, we treated the neutrophils with $0.3 \mathrm{mM}$ propionate for $10 \mathrm{~min}$ for the release of specific and gelatinase granules and with 30 $\mathrm{m} M$ propionate for $5 \mathrm{~min}$ for the release of azurophil granules in our subsequent experiments.

\section{Involvement of the Intracellular Inositol Triphosphate- $\mathrm{Ca}^{2+}$ Signaling Pathway in the Granule Release Induced by Propionate}

Calcium $\left(\mathrm{Ca}^{2+}\right)$ is a crucial secondary messenger in the activation of exocytosis (Burgos et al., 2011). We previously suggested that $30 \mathrm{~m} M$ propionate increased intracellular $\mathrm{Ca}^{2+}$ levels, either by extracellular influx or intracellular store release in bovine neutrophils (Sandoval et al., 2007a). To assess the influence of the intracellular $\mathrm{Ca}^{2+}$ fluxes on the release of granules after propionate stimulation, we used $2 \mu M$ U73122 (a PLC inhibitor), $50 \mu M$ 2-APB (a putative SOCE inhibitor), and $0.3 \mathrm{~m} M$ EGTA to minimize the extracellular $\mathrm{Ca}^{2+}$ concentration. We first verified that the concentrations of the inhibitors used in these experiments were sufficient to reduce intracellular $\mathrm{Ca}^{2+}$ flux induced by propionate. As shown in Figure 3A and B, propionate at $30 \mathrm{mM}$ and $0.3 \mathrm{mM}$ slightly increased the intracellular $\mathrm{Ca}^{2+}$ levels. This response was completely abolished when the cells were incubated with U73122 for 5 min (Figure 3C and D) or 2-APB for 10 min (Figure 3E and F) before stimulating with propionate. In the absence of external calcium and presence of $0.3 \mathrm{mM}$ EGTA for 30 $\mathrm{s}$, the calcium flux elicited by propionate was supressed (Figure 3G and $\mathrm{H}$ ). It is known that EGTA induces a decrease of flurorescence that can be explained by chelation of $\mathrm{Ca}^{2+}$ traces in the medium observed in this type of assay (Hulme, 1990). To assess the role of the intracellular $\mathrm{Ca}^{2+}$ influx in granule release induced by propionate, the neutrophils were treated with U73122, 2-APB, and EGTA for the times mentioned above. As shown in Figure 3J and 3K, treating neutrophils with U73122 significantly reduced $(P<0.05)$ the release of lactoferrin and MMP-9 induced by propionate. Treatment with U73122 showed a tendency to increase the MPO release induced by propionate (Figure 3I). We observed that $50 \mu M 2$-APB $(P<0.05)$ only reduced release of lactoferrin and MMP-9 (Figure 3J and K) but not that of MPO (Figure 3I). Finally, the treatment of neutrophils with $0.3 \mathrm{~m} M$ EGTA significantly reduced $(P<0.05)$ the release of lactoferrin (Figure $3 \mathrm{~J})$ and MMP-9 (Figure 3K) induced by propionate. In contrast, no effect on primary granules was observed by treating the neutrophils with EGTA (Figure 3I).

\section{The MAPK ERK1/2 and $G_{i / 0}$ Protein Are Needed for Propionate-Mediated MPO and Lactoferrin Release from Bovine Neutrophils}

The release of each type of granule is differentially regulated by intracellular signaling pathways such as those involving MAPK, protein kinase C (PKC), and Src-family kinases (Lacy and Eitzen, 2008). To determinate if the granule release induced by propionate is mediated by these signaling pathways, we used the specific pharmacological inhibitors UO126 and SB203580 to inhibit the ERK1/2 and p38 MAPK pathways, respectively. We also used Src kinase inhibitor I, a potent inhibitor of Src family tyrosine kinases, and LY294002, a specific PI3K inhibitor. The neutrophils were incubated for $10 \mathrm{~min}$ with the inhibitors before the stimulation with propionate. Our results indicate that MPO and lactoferrin release induced by propionate was inhibited by UO126 (Figure 4A and B). The MMP-9 release in response to propionate was partially inhibited by the PI3K inhibitor LY284002 (Figure 4C). We observed no effect of blocking the p38 pathway and Src kinases on granule release induced by propionate (Figure 4A, B and C).

The incubation of neutrophils with the vehicle (DMSO) did not induce the release of the granules and did not modify the effect of propionate (data not shown). To examine whether PT, an inhibitor of $\mathrm{G}_{\mathrm{i} / \mathrm{o}}$ protein activation, affected granule release induced by propionate, we treated bovine neutrophils with 200 $\mathrm{ng} / \mathrm{mL}$ PT for $1 \mathrm{~h}$. Our data showed that PT significantly inhibited the propionate-mediated MPO and lactoferrin release (Figure $4 \mathrm{~A}$ and $\mathrm{B}$ ) in the bovine neutrophils, suggesting a role for $\mathrm{G}_{\mathrm{i} / \mathrm{o}}$ proteins in these responses. 
A

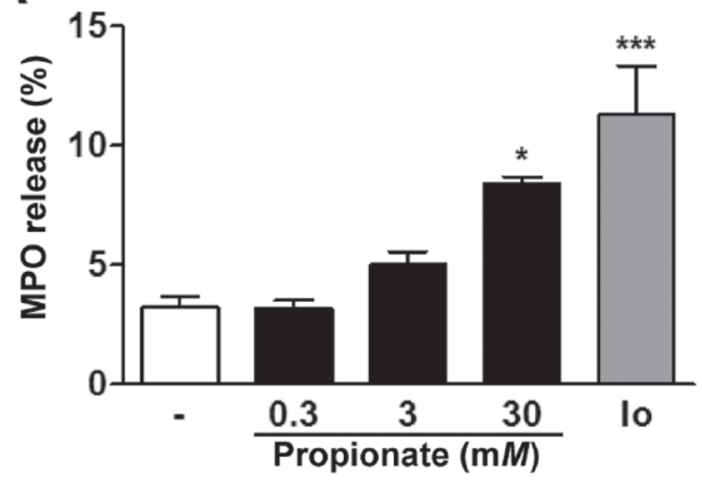

C

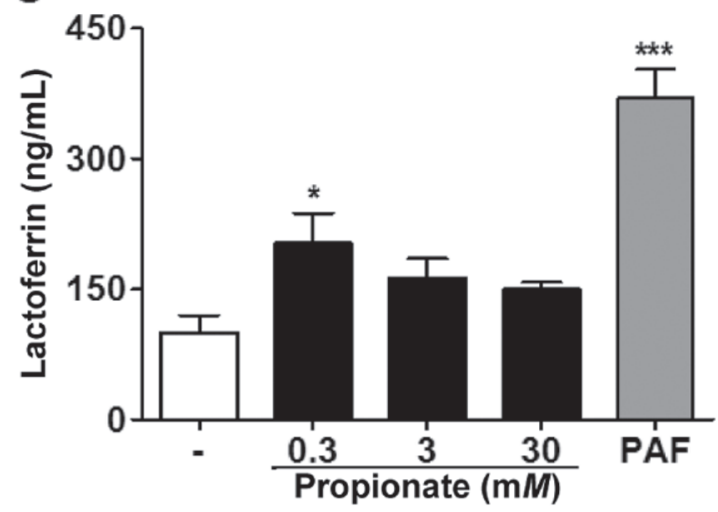

E

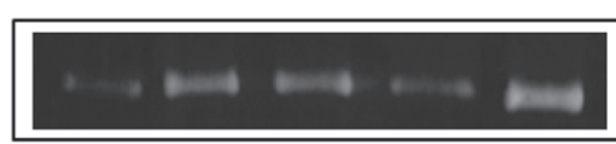

$\mathrm{kDa}$ $-72$
B

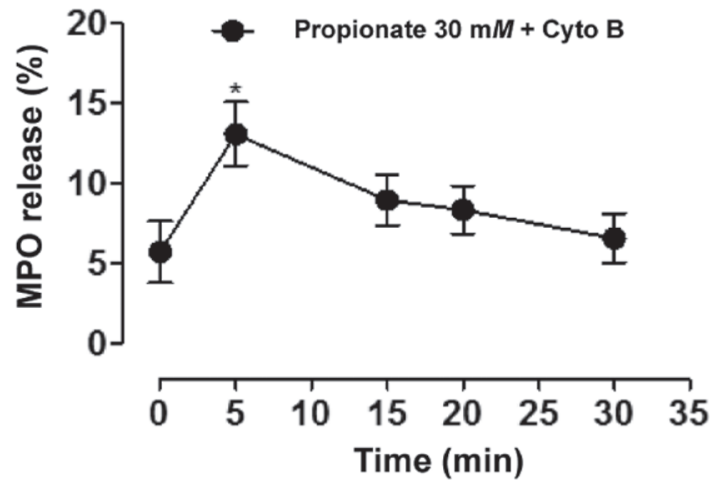

D

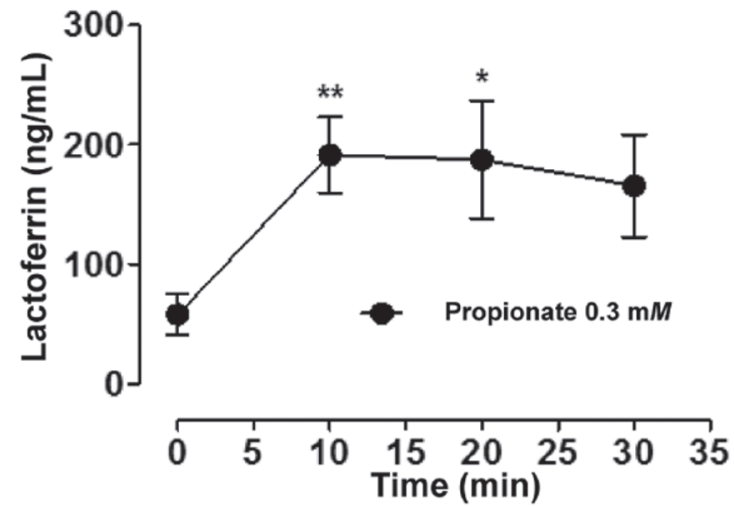

F

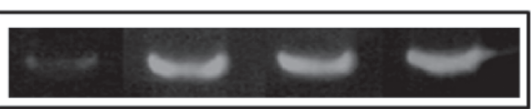

kDa $-72$

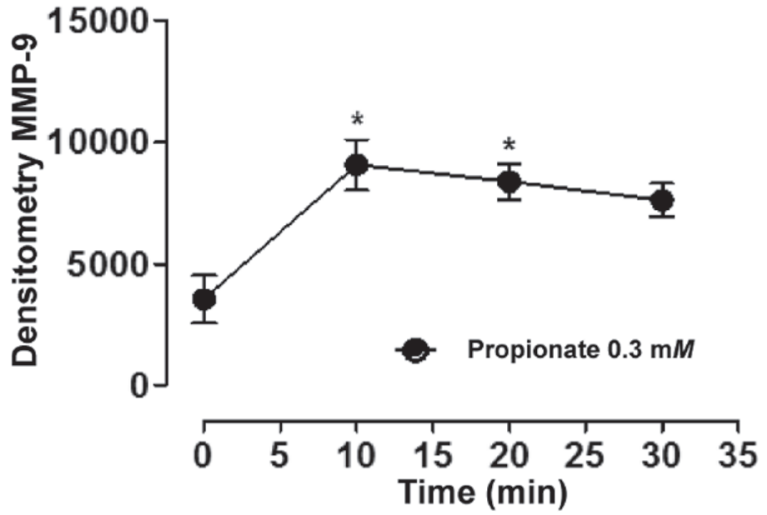

Figure 2. Propionate-induced granule release from bovine neutrophils. (A) Neutrophils were treated with $0.3,3$, or $30 \mathrm{~m} M$ propionate or 5 $\mu \mathrm{g} / \mathrm{mL}$ ionomycin (Io; positive control) for $30 \mathrm{~min}$ in the presence of $5 \mu \mathrm{g} / \mathrm{mL}$ cytochalasin B (Cyto B). Neutrophils were treated with propionate or $100 \mathrm{nM}$ platelet-activating factor (PAF) as a positive control for $10 \mathrm{~min}(\mathrm{C})$ or $30 \mathrm{~min}$ (E). The cell-free supernatants were collected and assayed for the presence of MPO, lactoferrin, and MMP-9. The panels on the right show kinetics of myeloperoxidase (MPO; B), lactoferrin (D), and matrix metalloprotease-9 (MMP-9; F) release in response to 0.3 or $30 \mathrm{~m} M$ propionate from bovine neutrophils. The cells were incubated with propionate for times varying from 0 to $30 \mathrm{~min}$. For panels $\mathrm{A}, \mathrm{C}$, and $\mathrm{E}$, each bar represents the mean $\pm \mathrm{SEM}$ of 4 experiments, ${ }^{*} P<0.05$, ${ }^{* * *} P<0.001$, compared with the control. For panels B, D, and $\mathrm{F}$, the data represent the mean \pm SEM of 5 experiments, ${ }^{*} P<0.05,{ }^{* *} P<$ 0.01 , compared with the control at each time. 
A

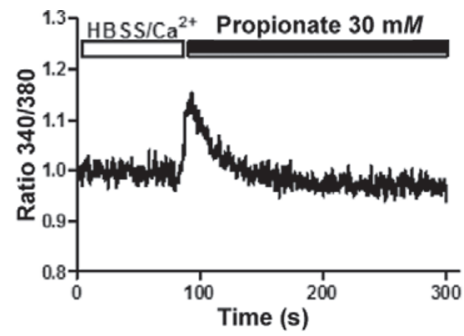

C
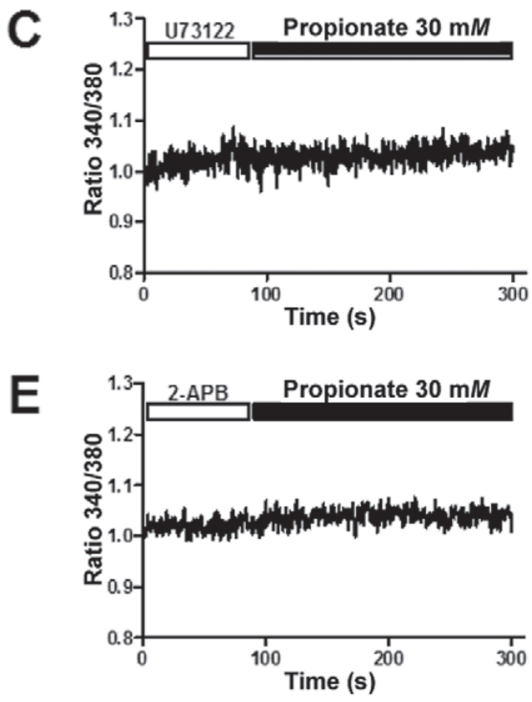

G

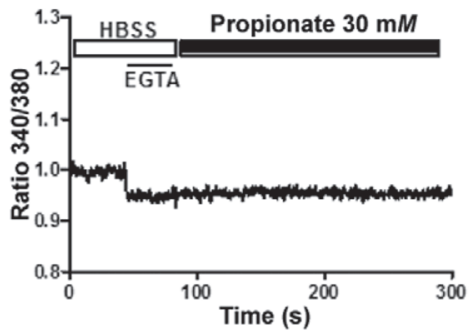

B
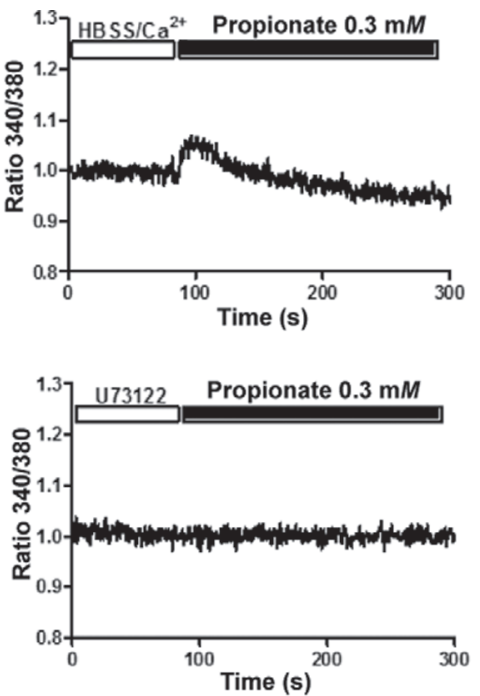

$\mathbf{F}$

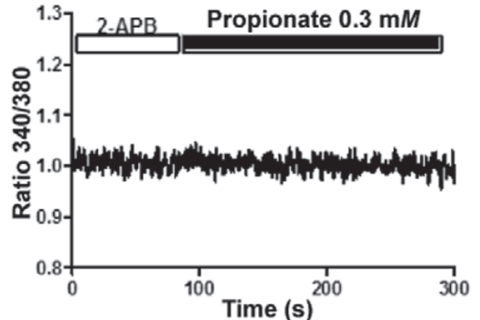

$\mathrm{H}$

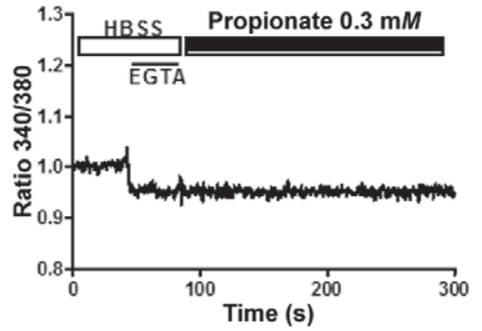

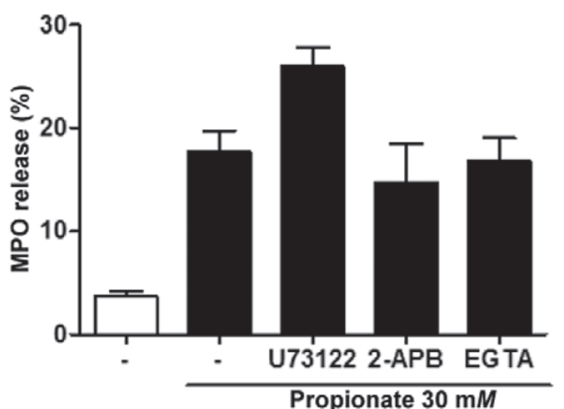

J

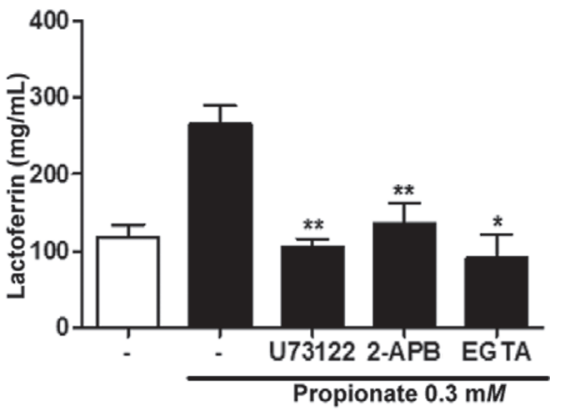

K

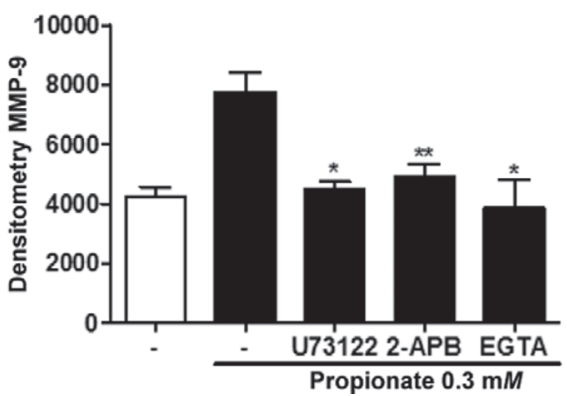

Figure 3. Inhibition of calcium influx affects propionate-mediated matrix metalloprotease-9 (MMP-9) and lactoferrin release but not myeloperoxidase (MPO) release. Effect of (A) $30 \mathrm{mM}$ or (B) $0.3 \mathrm{mM}$ propionate on calcium influx measured as the increase in the fluorescence ratio 340:380 in cells loaded with fura 2-AM (a $\mathrm{Ca}^{2+}$-sensitive fluorophore; Molecular Probes, Eugene, OR). Neutrophils were incubated for 5 min with $2 \mu M$ U73122 (a phospholipase C inhibitor; Calbiochem, La Jolla, CA; panels C, D), for 10 min with $50 \mu M 2$-aminoethoxydiphenyl borate (2-APB, a putative store-operated calcium entry inhibitor; Sigma Chemical Co., St. Louis, MO; panels E, F), or for $30 \mathrm{~s}$ with $0.3 \mathrm{mM}$ ethylene glycol tetraacetic acid (EGTA; G, H) and then stimulated with propionate. The black horizontal lines indicate the application time of propionate, HBSS = Hanks' balanced salt solution; the data represent 3 independent experiments. Effect of U73122, 2-APB, and EGTA on the release of MPO (I), lactoferrin $(\mathrm{J})$, and MMP-9 $(\mathrm{K})$ induced by propionate. Each bar represents the mean $\pm \mathrm{SEM}$ of 5 experiments; ${ }^{*} P<0.05$, ${ }^{*} * P<0.01$, compared with the propionate treatment.

\section{Presence of G Protein-Coupled Receptors for SCFA in Bovine Neutrophils}

The GPR 41 and GPR $43 \mathrm{mRNA}$ are widely expressed in cattle, including in the rumen and pancreas (Wang et al., 2009), but until now, it was not known whether these receptors were expressed in bovine neutrophils. The presence of GPR 41 and GPR $43 \mathrm{mRNA}$ in bovine neutrophils was analyzed by RT-PCR using the primers designed by Wang et al. (2009). The obtained products were 323 and $214 \mathrm{bp}$, respectively, consistent with the sizes predicted from GenBank sequences. We observed that the expression level of the GPR 43 mRNA was notably higher than that of GPR 41 (Figure 5A). The expression levels of the GPR 41 and GPR 43 mRNA were analyzed using real-time PCR. We observed that the relative abundance of $G P R 43$ was 35-fold greater than that of GPR 41 in bovine neutrophils (Figure 5B).

Phenylacetamides 1 and 2 were recently described as synthetic agonists of the GPR43 receptor (Lee et 
al., 2008). To determine if phenylacetamides 1 and 2 could activate the GPR43 receptor and transduce a signal in bovine neutrophils, we treated the neutrophils with increasing concentrations (100 n $M$ to $10 \mu M$ ) of the GPR43 agonists and monitored the $\mathrm{Ca}^{2+}$ influx with fura-2AM fluorescence analysis. We observed that phenylacetamides 1 and 2 caused a transient increase in $\mathrm{Ca}^{2+}$ influx. The dose-response curves in Figure $5 \mathrm{C}$ show that phenylacetamide 2 displayed stronger potency than phenylacetamide 1 .

\section{Phenylacetamides 1 and 2 Induce Granule Release from Bovine Neutrophils}

To determine the effect of the GPR43 agonists on granule release, we treated bovine neutrophils with phenylacetamides 1 and 2 in the range of $100 \mathrm{n} M$ to $10 \mu \mathrm{M}$ for $10 \mathrm{~min}$, and the release of MPO, lactoferrin, and MMP-9 was measured in the supernatants. Both agonists induced lactoferrin (Figure 6B) and MMP-9 (Figure 6C) release, with a higher efficacy for phenylacetamide 2, as shown in the dose-response curves. Only high concentrations of both agonists induced MPO release (Figure 6A).

\section{DISCUSSION}

In the present study, we found that stimulation of bovine neutrophils with millimolar concentrations of propionate induced degranulation in bovine neutrophils, as demonstrated by the observation that propionate increased the secretion of MPO, lactoferrin, and MMP-9, which are markers of azurophilic, specific granules, and gelatinase granules, respectively. In a similar manner to propionate, chemoattractants including PAF and IL- 8 have been shown to induce a quick release of MPO (Quade and Roth, 1997; Swain et al., 1998), lactoferrin (Swain et al., 2000), and MMP-9 (Conejeros et al., 2012) from bovine neutrophils within $15 \mathrm{~min}$. In addition to identifying this novel property for propionate in bovine neutrophil function, we provided evidence that this activity might occur through the free fatty acid receptor GPR43 because 2 synthetic agonists, phenylacetamides 1 and 2, were able to induce lactoferrin and MMP-9 release from bovine neutrophils. We also showed for the first time that the mRNA for the bovine orthologs of GPR41 and GPR43 are expressed in bovine neutrophils. The expression level of GPR 43 mRNA was remarkably higher than that of GPR 41, as demonstrated by RT-PCR and real-time PCR. In accordance with this result, other researchers have demonstrated a highly selective expression of GPR43 in human neutrophils (Brown et al., 2003; Le Poul et al., 2003). These receptors are expressed
A

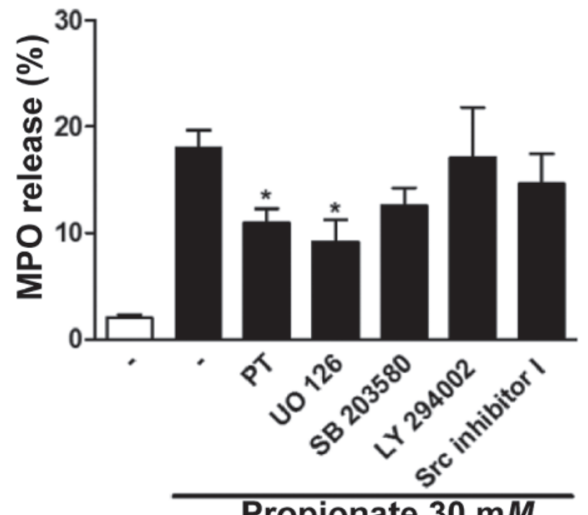

B

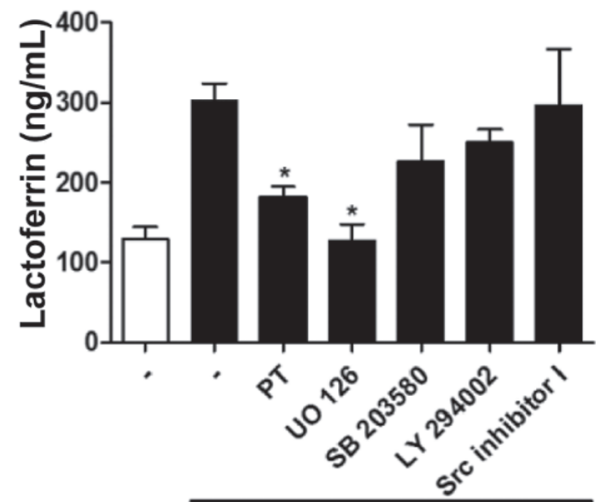

Propionate $0.3 \mathrm{~m} M$

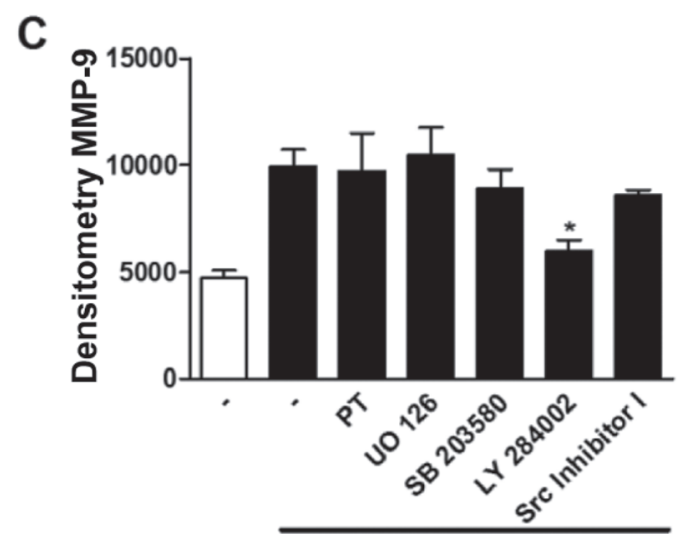

Propionate $0.3 \mathrm{mM}$

Figure 4. Effect of pertussis toxin (PT; Calbiochem, La Jolla, CA) and signal transduction inhibitors on the release of myeloperoxidase (MPO; A), lactoferrin (B), and matrix metalloprotease-9 (MMP-9; C) induced by propionate. Neutrophils were pretreated for $1 \mathrm{~h}$ with $200 \mathrm{ng} / \mathrm{mL}$ of PT or for $10 \mathrm{~min}$ with $10 \mu M$ UO126 [a mitogen-activated protein kinase (MAPK) MEK1/2 inhibitor; Calbiochem], $1 \mu M$ SB203580 (a p38 MAPK inhibitor; Calbiochem), $1 \mu M$ LY294002 (a phosphatidylinositol 3-kinase inhibitor; Promega, Madison, WI), and $0.1 \mu M$ Src inhibitor I (a potent inhibitor of Src family tyrosine kinases; Calbiochem) before stimulation with 30 or $0.3 \mathrm{mM}$ propionate. Each bar represents the mean \pm SEM of 4 experiments, ${ }^{*} P<0.05$, compared with the propionate treatment. 
A
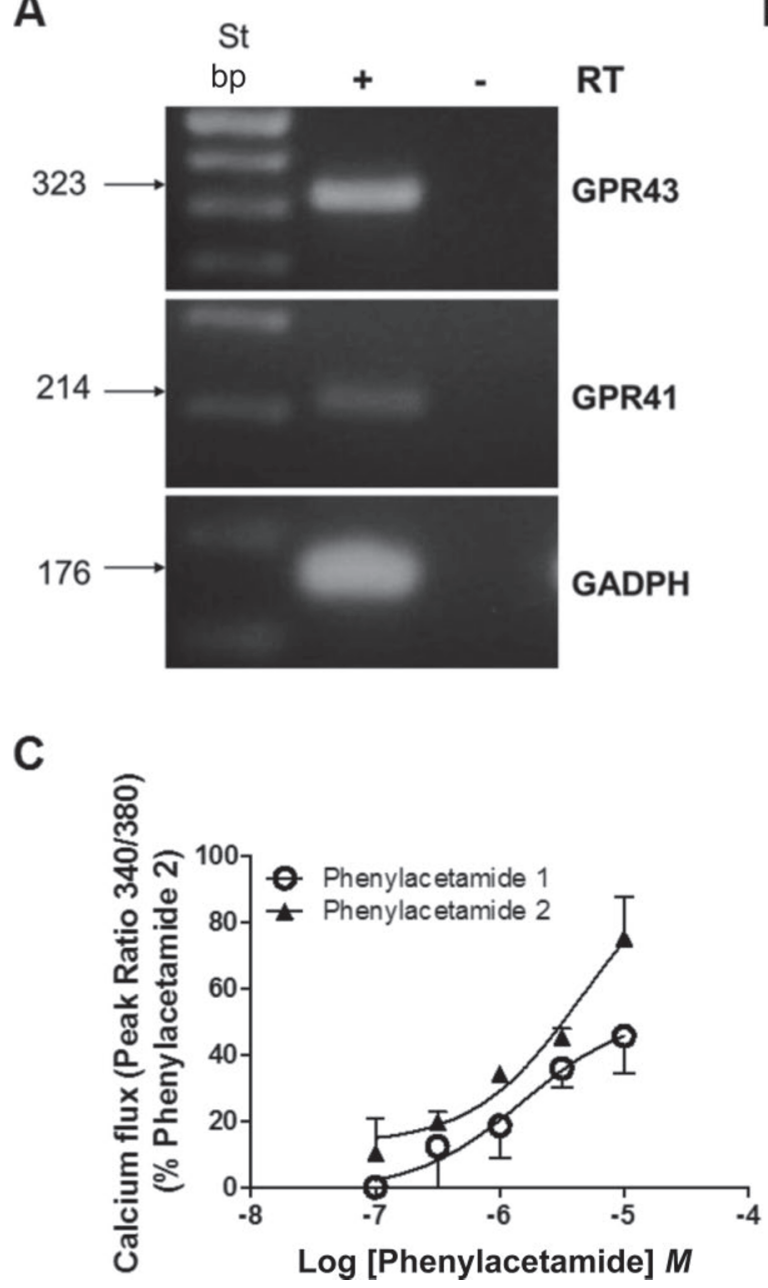

B

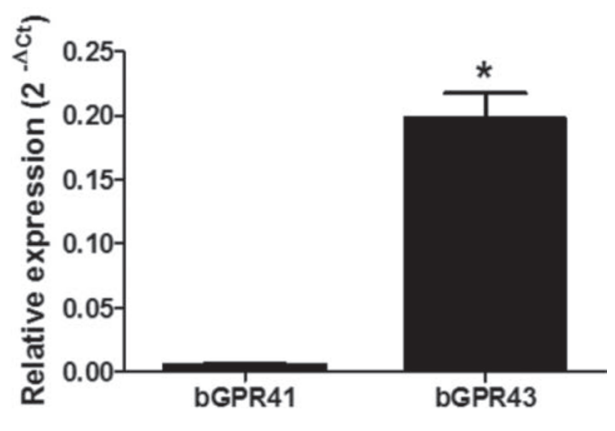

Figure 5. Expression of $\mathrm{G}$ protein-coupled receptor GPR41 and GPR43 mRNA in bovine neutrophils and effect of GPR43 agonists on calcium flux. (A) The expression of GPR 41 and GPR $43 \mathrm{mRNA}$ in bovine neutrophils was detected by reverse transcription (RT)-PCR. To exclude amplification from genomic DNA contamination, RNA was either treated with DNase before the RT reaction (RT+) or run without RT (negative control, RT-). A 100-bp DNA ladder in the left lane was used as a molecular size marker (St pb). The sizes of the GPR 43 , GPR 41 , and GAPDH PCR products were 214, 323, and $176 \mathrm{bp}$, respectively. (B) The samples were analyzed by real-time PCR. Relative abundance $=2^{(-\Delta \mathrm{Ct})}$, where $\Delta \mathrm{Ct}=$ cycle threshold $(\mathrm{Ct})$ GPR 41 or $\mathrm{Ct} G P R 43$ minus Ct GAPDH. The data are expressed as the mean $\pm \mathrm{SEM}$ of 3 experiments, $* P$ $<0.05$, compared with the relative expression of GPR41. (C) Concentration-response curves of phenylacetamides 1 and 2 on calcium influx in bovine neutrophils. Cells loaded with fura 2-AM (a $\mathrm{Ca}^{2+}$-sensitive fluorophore; Molecular Probes, Eugene, OR) were stimulated with $100 \mathrm{n} M$ to $10 \mu M$ of both agonists, and the peak of the calcium influx was determined. Each point represents the mean \pm SEM of 3 experiments.

in several organs (e.g., rumen and spleen in cattle), suggesting that GPR41 and GPR43 might mediate the regulatory effects of VFA in cattle, such as those on rumen development and the immune response (Wang et al., 2009). The high expression of GPR $43 \mathrm{mRNA}$ in bovine neutrophils supports the possibility that this receptor might mediate the granule release induced by propionate. Thus, propionate is one of the most potent natural agonists for both GPR41 and GPR43 (Le Poul et al., 2003). Similar to observations in humans, bovine GPR41 and GPR43 couple to Gai/11, as demonstrated by the inhibition of reporter gene expression from a cyclic AMP (cAMP)-response promoter in cells caused by their interaction with SCFA (Wang et al., 2009). However, differential coupling to $\mathrm{G}$ proteins depending on the receptor subtype that is activated has also been described: GPR41 coupled exclusively though the PTsensitive $\mathrm{G}_{\mathrm{i} / \mathrm{o}}$ family, whereas GPR43 displayed dual coupling through the $\mathrm{G}_{\mathrm{i} / \mathrm{o}}$ and $\mathrm{G}_{\mathrm{q}}$ protein families (Le Poul et al., 2003). These 2 receptors signal through inositol 1,4,5-trisphosphate formation, intracellular $\mathrm{Ca}^{2+}$ release, ERK1/2 activation, and the inhibition of cAMP accumulation (Le Poul et al., 2003). Our results showed that the release of lactoferrin and MPO induced by propionate are partially PT sensitive. In contrast, the MMP-9 release induced by propionate was not affected 
A
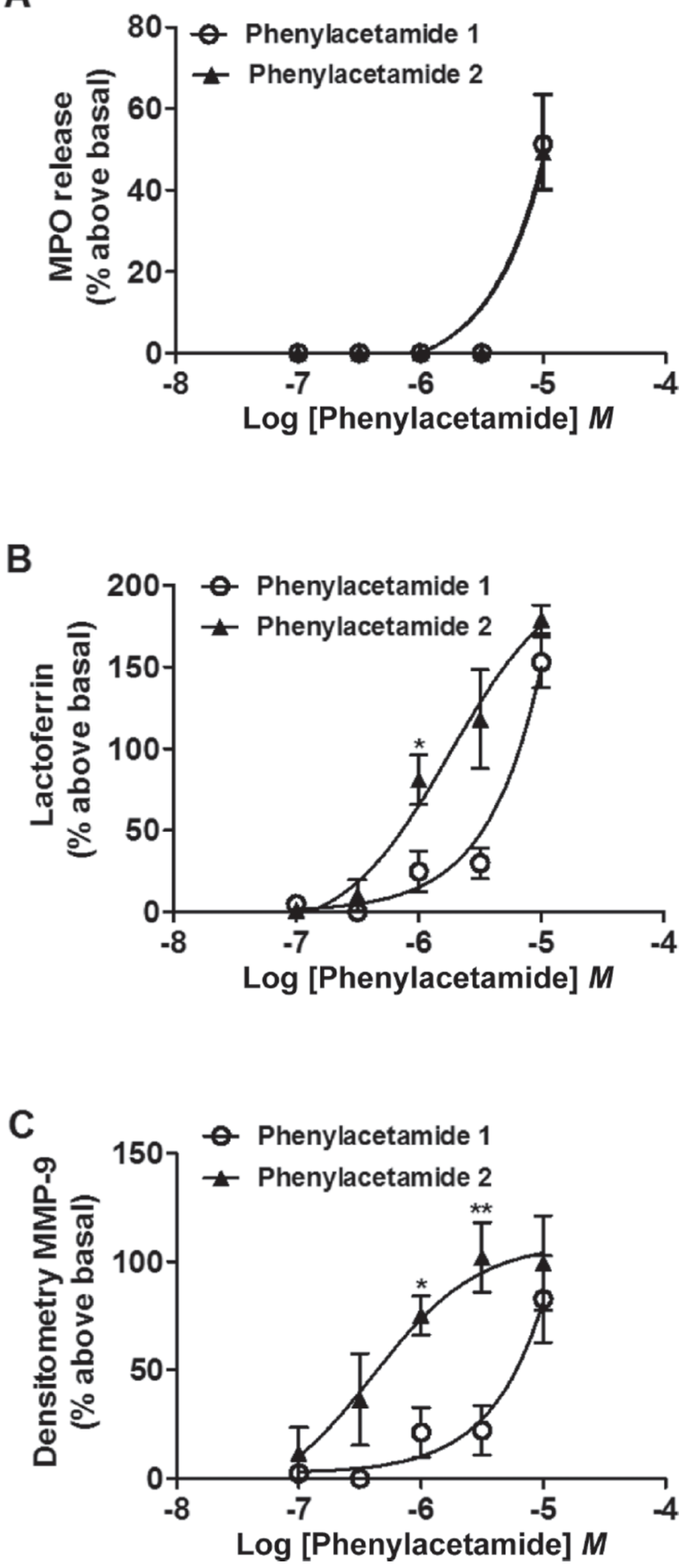

Figure 6. The G protein-coupled receptor GPR43 agonists phenylacetamide 1 and 2 induce granule release from bovine neutrophils. The cells were stimulated with $100 \mathrm{n} M$ to $10 \mu M$ of both agonists for $10 \mathrm{~min}$, and the cell-free supernatants were collected and assayed for the presence of $(\mathrm{A})$ myeloperoxidase (MPO), (B) lactoferrin, and $(\mathrm{C})$ matrix metalloprotease-9 (MMP-9). The dose-response curves were expressed as the percentage increase above the basal unstimulated level. Each point represents the mean \pm SEM of 5 experiments, ${ }^{*} P<$ $0.05,{ }^{* *} P<0.01$. by PT treatment. These observations suggest that the release of this type of granule is not dependent on the $\mathrm{G}_{\mathrm{i} / \mathrm{o}}$ protein.

It is widely known that granule release depends on changes in the intracellular $\mathrm{Ca}^{2+}$ level induced by agonists, such as fMLP, PAF, tumor necrosis factor (TNF)- $\alpha$ and Ig-zymosan (Burgos et al., 2011). Propionate at millimolar concentrations induces an increase in the cytoplasmic concentration of calcium in a similar fashion as chemotactic factors in human neutrophils (Le Poul et al., 2003). The mobilization of calcium elicited by propionate is derived from internal and external sources of $\mathrm{Ca}^{2+}$ in both human and bovine neutrophils (Sandoval et al., 2007a). Our findings show that an intracellular source of $\mathrm{Ca}^{2+}$ is required for the release of specific and gelatinase granules induced by propionate. This response also depends on PLC activation. In contrast, others studies have shown that the chelation of intracellular calcium has no effect on the release of MMP-9 mediated by IL-8 and TNF- $\alpha$ in human neutrophils (Chakrabarti and Patel, 2005; Chakrabarti et al., 2006). This result suggests a differential response depending on the type of ligand used. In support, the MMP-9 release induced by oleic acid (a long-chain monounsaturated fatty acid GPR40 agonist) was mostly dependent on calcium influx in bovine neutrophils (Hidalgo et al., 2011). In fact, our results demonstrated that the lactoferrin and MMP-9 release induced by propionate is dependent on calcium influx, because the chelation of extracellular calcium by EGTA significantly reduced the lactoferrin and MMP-9 release. Moreover, neutrophils treated with 2-APB, a potent SOCE inhibitor, in bovine neutrophils (Sandoval et al., 2007b), reduced the release of lactoferrin and MMP-9 induced by propionate. Previously, we determined that 2-APB at concentrations of $50 \mu M$ did not affect intracellular calcium release and only reduced the SOCE phenomenon (Sandoval et al., 2007b). The specific target molecule for calcium in granule exocytosis has not yet been identified, but $\mathrm{Ca}^{2+}$ sensors, such as annexins, PKC, and calmodulin, have been suggested to play a role in this process (Lacy and Eitzen, 2008). Intracellular pathways, such as those involving the MAPK family, which includes ERK1/2, the c-Jun $\mathrm{NH}_{2}$-terminal kinases, and p38 MAPK, have been shown to mediate granule exocytosis (Downey et al., 1998; Mócsai et al., 2000; Chakrabarti et al., 2006). Neutrophil chemoattractants act through Gicoupled G protein-coupled receptor, and PI3K, MAPK, and Rac1/2 signaling pathways have been implicated downstream in the regulatory networks controlling neutrophil function (Lacy and Eitzen, 2008). In this study, we demonstrated that the MAP kinase ERK1/2 is involved in the MPO and lactoferrin release induced 
by propionate, but this pathway was not involved in the MMP-9 release, given that UO126 did not modify the MMP-9 release induced by propionate. However, other studies have shown that the MMP-9 release induced by IL- 8 is controlled by ERK1/2 but not p38 MAPK (Chakrabarti and Patel, 2005) and that Lys-des[Arg9]bradykinin (LDBK), a bradykinin B1 receptor agonist, was dependent on both signaling pathways (Ehrenfeld et al., 2009). Compared with other chemoattractants, propionate induces a weaker ERK1/2 phosphorylation in bovine neutrophils (Sandoval et al., 2007a), suggesting that other signaling pathways could be involved in the MMP-9 release induced by propionate. We observed a significant inhibition of gelatinase granule release when the neutrophils were incubated with the PI3K inhibitor LY284002, and this effect was not affected by PT, suggesting that MMP-9 release is not dependent on $\mathrm{G}_{\mathrm{i} / \mathrm{o}}$ proteins. In accordance with this result, others studies have demonstrated that opsonized zymosan and heat-aggregated IgG induce the MMP-9 release that was inhibited by wortmannin, a PI3K inhibitor, in bovine neutrophils (Higuchi et al., 2007).

In addition to propionate, which can activate GPR43, 2 synthetic small molecule phenylacetamides have recently been described as selective agonists for GPR43. In several assays, including the inhibition of cAMP levels and elevation of $\left.{ }^{35} \mathrm{~S}\right] \mathrm{GTP} \gamma \mathrm{S}$ binding, these ligands acted as direct agonists of GPR43, with a higher potency than propionate (Lee et al., 2008). Additionally, the phenylacetamides in combination with the endogenous ligands acted as positive allosteric modulators of the function of the SCFA, as demonstrated by cAMP assays and calcium flux assays (Lee et al., 2008). In our assays, phenylacetamides 1 and 2 induced calcium flux and lactoferrin and MMP-9 release in a concentrationdependent manner, suggesting that the GPR43 receptor is involved in propionate-mediated granule release. Recent data demonstrated that SCFA induce the chemotaxis of mouse neutrophils in vitro, an effect that is dependent on the activation of GPR43, given that the effects of SCFA were mimicked by phenylacetamide 1 and were abolished in GPR $43^{-/-}$mouse bone marrowderived neutrophils in vitro (Vinolo et al., 2011a).

The expression of receptors for SCFA in bovine neutrophils opens new perspectives in the modulation of the immune system functions in pathophysiological situations in cattle. Neutrophils are critical in host defense, but the inappropriate infiltration and activation of neutrophils can lead to severe tissue damage (Segel et al., 2011). The ingestion of excessive amounts of highly fermentable concentrates is followed by an increase in propionic acid production. In this environment, cellulolytic and lactate-using bacteria and protozoa are destroyed, while the growth of lactobacilli is promoted, increasing D-lactic acid production and decreasing the $\mathrm{pH}$, which results in ruminal acidosis (Nocek, 1997). Ruminal acidosis is the major insult leading to barrier failure in the rumen and has been associated with a high incidence of ruminal wall lesions and ruminal parakeratosis. This condition is characterized by accumulated layers of keratinized, nucleated squamous epithelial cells and excessive sloughing of the epithelium (Hinders and Owen, 1965). During the early stages of a grain-induced ruminal acidosis, an increased infiltration of the upper strata of the ruminal epithelium with lymphocyte-like cells is observed (Steele et al., 2009). In addition, intraruminal infusion of specific SCFA can cause erosion of the tight junctions between cells and the formation of lesions (Costa et al., 2008). The rumen epithelium acts as a protective barrier preventing translocation of bacteria into the portal circulation (Graham and Simmons, 2005). The local ruminal epithelial tissue damage becomes systemic when endotoxins or microbes translocate into the portal blood stream, thus causing liver abscesses and an array of immunological responses (Nocek, 1997). We suggest that the neutrophil granule release induced by propionate may contribute with neutrophil infiltration and tissue damage in ruminants during grain overload. In addition, hindgut acidosis can occur as a consequence of ruminal acidosis when poor selective retention of fermentable carbohydrates by the rumen increases carbohydrate flow to the hindgut. In more severe situations, hindgut acidosis is characterized by an inflammatory response (Gressley et al., 2011). In fact, SCFA, through direct actions on the GPR43 receptor in neutrophils, are implicated in the effects of gut microbiota on intestinal inflammation. Moreover, GPR43 knockout mice exhibited less severe inflammation and a decrease in neutrophil infiltration in experimental colitis model (Sina et al., 2009).

\section{CONCLUSIONS}

Propionate induces granule release from bovine neutrophils, a process that is likely mediated mainly by GPR43 receptors. These results support the existence of a link between VFA metabolism and the control of the inflammatory and immune responses in bovines.

\section{ACKNOWLEDGMENTS}

This work was supported by grant 1090401 and 1120718 from the Chilean National Science and Technology Research Fund (FONDECYT; Chile). The authors greatly acknowledge the Improvement Program Quality and Equity in Higher Education (MECESUP) of the 
Ministry of Education for the maintenance scholarship of Project UCO0606 and DID-UACh, supporting M. D. Carretta.

\section{REFERENCES}

Bergman, E. N. 1990. Energy contributions of volatile fatty acids from the gastrointestinal tract in various species. Physiol. Rev. 70:567-590.

Borregaard, N., O. E. Sorensen, and K. Theilgaard-Monch. 2007. Neutrophil granules: A library of innate immunity proteins. Trends Immunol. 28:340-345.

Brown, A. J., S. M. Goldsworthy, A. A. Barnes, M. M. Eilert, L. Tcheang, D. Daniels, A. I. Muir, M. J. Wigglesworth, I. Kinghorn, N. J. Fraser, N. B. Pike, J. C. Strum, K. M. Steplewski, P. R. Murdock, J. C. Holder, F. H. Marshall, P. G. Szekeres, S. Wilson, D. M. Ignar, S. M. Foord, A. Wise, and S. J. Dowell. 2003. The orphan G protein-coupled receptors GPR41 and GPR43 are activated by propionate and other short chain carboxylic acids. J. Biol. Chem. 278:11312-11319.

Brown, G. B., and J. A. Roth. 1991. Comparison of the response of bovine and human neutrophils to various stimuli. Vet. Immunol. Immunopathol. 28:201-218.

Brunkhorst, B. A., E. Kraus, M. Coppi, M. Budnick, and R. Niederman. 1992. Propionate induces polymorphonuclear leukocyte activation and inhibits formylmethionyl-leucyl-phenylalanine-stimulated activation. Infect. Immun. 60:2957-2968.

Burgos, R. A., I. Conejeros, M. A. Hidalgo, D. Werling, and C. Hermosilla. 2011. Calcium influx, a new potential therapeutic target in the control of neutrophil-dependent inflammatory diseases in bovines. Vet. Immunol. Immunopathol. 143:1-10.

Burvenich, C., V. Van Merris, J. Mehrzad, A. Diez-Fraile, and L. Duchateau. 2003. Severity of E. coli mastitis is mainly determined by cow factors. Vet. Res. 34:521-564.

Chakrabarti, S., and K. D. Patel. 2005. Regulation of matrix metalloproteinase-9 release from IL-8-stimulated human neutrophils. J. Leukoc. Biol. 78:279-288.

Chakrabarti, S., J. M. Zee, and K. D. Patel. 2006. Regulation of matrix metalloproteinase-9 (MMP-9) in TNF-stimulated neutrophils: novel pathways for tertiary granule release. J. Leukoc. Biol. $79: 214-222$.

Conejeros, I., E. Jara, M. D. Carretta, P. Alarcon, M. A. Hidalgo, and R. A. Burgos. 2012. 2-Aminoethoxydiphenyl borate (2-APB) reduces respiratory burst, MMP-9 release and CD11b expression, and increases l-selectin shedding in bovine neutrophils. Res. Vet. Sci. $92: 103-110$.

Costa, S. F., M. N. Pereira, L. Q. Melo, J. C. Resende, and M. L. Chaves. 2008. Lactate, propionate and, butyrate induced morphological alterations on calf ruminal mucosa and epidermis: I. Histological aspects. Arq. Bras. Med. Vet. Zoo. 60:1-9.

Cox, M. A., J. Jackson, M. Stanton, A. Rojas-Triana, L. Bober, M. Laverty, X. Yang, F. Zhu, J. Liu, S. Wang, F. Monsma, G. Vassileva, M. Maguire, E. Gustafson, M. Bayne, C. C. Chou, D. Lundell, and C. H. Jenh. 2009. Short-chain fatty acids act as antiinflammatory mediators by regulating prostaglandin $\mathrm{E}(2)$ and cytokines. World J. Gastroenterol. 15:5549-5557.

Downey, G. P., J. R. Butler, H. Tapper, L. Fialkow, A. R. Saltiel, B. B. Rubin, and S. Grinstein. 1998. Importance of MEK in neutrophil microbicidal responsiveness. J. Immunol. 160:434-443.

Ehrenfeld, P., C. E. Matus, F. Pavicic, C. Toledo, F. Nualart, C. B. Gonzalez, R. A. Burgos, K. D. Bhoola, and C. D. Figueroa. 2009. Kinin B1 receptor activation turns on exocytosis of matrix metalloprotease-9 and myeloperoxidase in human neutrophils: involvement of mitogen-activated protein kinase family. J. Leukoc. Biol. $86: 1179-1189$.

Faurschou, M., and N. Borregaard. 2003. Neutrophil granules and secretory vesicles in inflammation. Microbes Infect. 5:1317-1327.

Gennaro, R., B. Dewald, U. Horisberger, H. U. Gubler, and M. Baggiolini. 1983. A novel type of cytoplasmic granule in bovine neutrophils. J. Cell Biol. 96:1651-1661.
Graham, C., and N. L. Simmons. 2005. Functional organization of the bovine rumen epithelium. Am. J. Physiol. Regul. Integr. Comp. Physiol. 288:R173-R181.

Gressley, T. F., M. B. Hall, and L. E. Armentano. 2011. Ruminant Nutrition Symposium: Productivity, digestion, and health responses to hindgut acidosis in ruminants. J. Anim. Sci. 89:1120-1130.

Hidalgo, M. A., C. Nahuelpan, C. Manosalva, E. Jara, M. D. Carretta, I. Conejeros, A. Loaiza, R. Chihuailaf, and R. A. Burgos. 2011. Oleic acid induces intracellular calcium mobilization, MAPK phosphorylation, superoxide production and granule release in bovine neutrophils. Biochem. Biophys. Res. Commun. 409:280-286.

Higuchi, H., M. Ishizaka, and H. Nagahata. 2007. Complement receptor type 3 (CR3)- and $\mathrm{Fc}$ receptor $(\mathrm{FcR})$-mediated matrix metalloproteinase 9 (MMP-9) secretion and their intracellular signalling of bovine neutrophils. Vet. Res. Commun. 31:985-991.

Hinders, R. G., and F. G. Owen. 1965. Relation of ruminal parakeratosis development to volatile fatty acid absorption. J. Dairy Sci. 48:1069-1073.

Hulme, E. C. 1990. Receptor-Effector Coupling. A Practical Approach. Oxford University Press Inc., New York, NY.

Lacy, P., and G. Eitzen. 2008. Control of granule exocytosis in neutrophils. Front. Biosci. 13:5559-5570.

Le Poul, E., C. Loison, S. Struyf, J. Y. Springael, V. Lannoy, M. E. Decobecq, S. Brezillon, V. Dupriez, G. Vassart, J. Van Damme, M. Parmentier, and M. Detheux. 2003. Functional characterization of human receptors for short chain fatty acids and their role in polymorphonuclear cell activation. J. Biol. Chem. 278:25481-25489.

Lee, T., R. Schwandner, G. Swaminath, J. Weiszmann, M. Cardozo, J. Greenberg, P. Jaeckel, H. Ge, Y. Wang, X. Jiao, J. Liu, F. Kayser, H. Tian, and Y. Li. 2008. Identification and functional characterization of allosteric agonists for the $\mathrm{G}$ protein-coupled receptor FFA2. Mol. Pharmacol. 74:1599-1609.

Mócsai, A., Z. Jakus, T. Vantus, G. Berton, C. A. Lowell, and E. Ligeti. 2000. Kinase pathways in chemoattractant-induced degranulation of neutrophils: the role of p38 mitogen-activated protein kinase activated by Src family kinases. J. Immunol. 164:4321-4331.

Mortensen, P. B., and M. R. Clausen. 1996. Short-chain fatty acids in the human colon: relation to gastrointestinal health and disease. Scand. J. Gastroenterol. Suppl. 216:132-148.

Naccache, P. H., N. Faucher, A. C. Caon, and S. R. McColl. 1988. Propionic acid-induced calcium mobilization in human neutrophils. J. Cell. Physiol. 136:118-124.

Nakao, S., Y. Moriya, S. Furuyama, R. Niederman, and H. Sugiya. 1998. Propionic acid stimulates superoxide generation in human neutrophils. Cell Biol. Int. 22:331-337.

Nocek, J. E. 1997. Bovine acidosis: Implications on laminitis. J. Dairy Sci. 80:1005-1028.

Paape, M. J., D. D. Bannerman, X. Zhao, and J. W. Lee. 2003. The bovine neutrophil: Structure and function in blood and milk. Vet. Res. 34:597-627.

Quade, M. J., and J. A. Roth. 1997. A rapid, direct assay to measure degranulation of bovine neutrophil primary granules. Vet. Immunol. Immunopathol. 58:239-248.

Roth, J. A., and M. L. Kaeberle. 1981. Isolation of neutrophils and eosinophils from the peripheral blood of cattle and comparison of their functional activities. J. Immunol. Methods 45:153-164.

Sandoval, A., F. Trivinos, A. Sanhueza, D. Carretta, M. A. Hidalgo, J. L. Hancke, and R. A. Burgos. 2007a. Propionate induces pH(i) changes through calcium flux, ERK1/2, p38, and PKC in bovine neutrophils. Vet. Immunol. Immunopathol. 115:286-298.

Sandoval, A. J., J. P. Riquelme, M. D. Carretta, J. L. Hancke, M. A. Hidalgo, and R. A. Burgos. 2007b. Store-operated calcium entry mediates intracellular alkalinization, ERK1/2, and Akt/PKB phosphorylation in bovine neutrophils. J. Leukoc. Biol. 82:12661277.

Segel, G. B., M. W. Halterman, and M. A. Lichtman. 2011. The paradox of the neutrophil's role in tissue injury. J. Leukoc. Biol. 89:359-372.

Sengeløv, H., L. Kjeldsen, and N. Borregaard. 1993. Control of exocytosis in early neutrophil activation. J. Immunol. 150:1535-1543. 
Sina, C., O. Gavrilova, M. Forster, A. Till, S. Derer, F. Hildebrand, B. Raabe, A. Chalaris, J. Scheller, A. Rehmann, A. Franke, S. Ott, R. Hasler, S. Nikolaus, U. R. Folsch, S. Rose-John, H. P. Jiang, J. Li, S. Schreiber, and P. Rosenstiel. 2009. G protein-coupled receptor 43 is essential for neutrophil recruitment during intestinal inflammation. J. Immunol. 183:7514-7522.

Steele, M. A., O. AlZahal, S. E. Hook, J. Croom, and B. W. McBride. 2009. Ruminal acidosis and the rapid onset of ruminal parakeratosis in a mature dairy cow: A case report. Acta Vet. Scand. 51:39.

Swain, S. D., P. L. Bunger, K. M. Sipes, L. K. Nelson, K. L. Jutila, S. M. Boylan, and M. T. Quinn. 1998. Platelet-activating factor induces a concentration-dependent spectrum of functional responses in bovine neutrophils. J. Leukoc. Biol. 64:817-827.

Swain, S. D., K. L. Jutila, and M. T. Quinn. 2000. Cell-surface lactoferrin as a marker for degranulation of specific granules in bovine neutrophils. Am. J. Vet. Res. 61:29-37.
Vinolo, M. A., G. J. Ferguson, S. Kulkarni, G. Damoulakis, K. Anderson, Y. M. Bohlooly, L. Stephens, P. T. Hawkins, and R. Curi 2011a. SCFAs induce mouse neutrophil chemotaxis through the GPR43 receptor. PLoS ONE 6:e21205.

Vinolo, M. A., H. G. Rodrigues, R. T. Nachbar, and R. Curi. 2011b. Regulation of inflammation by short chain fatty acids. Nutrients $3: 858-876$

Wang, A., Z. Gu, B. Heid, R. M. Akers, and H. Jiang. 2009. Identification and characterization of the bovine $\mathrm{G}$ protein-coupled receptor GPR41 and GPR43 genes. J. Dairy Sci. 92:2696-2705.

Zapolska-Downar, D., and M. Naruszewicz. 2009. Propionate reduces the cytokine-induced VCAM-1 and ICAM-1 expression by inhibiting nuclear factor-kappa B (NF-kappaB) activation. J. Physiol. Pharmacol. 60:123-131. 